\title{
SAGE-B: a dynamic dam-break flood emergency management system
}

\author{
G. de Jesus, M. A. Santos \& J. Palha-Fernandes \\ Laboratório Nacional de Engenharia Civil, Portugal
}

\begin{abstract}
The emergency management of a specific dam is generally based on emergency plans that contain static data related to the dam and to all elements associated to the emergency. Fundamental data, such as information about the population located in the areas at risk or the vehicles available for rescue that are located in the areas impacted by the predicted flood, are always changing, so new versions of the emergency plans are frequently issued without achieving an effective update of the required information for emergency management. In order to support and automatically update this process, SAGE-B, a new, dynamic information system that supports dam-induced emergency management, was developed at LNEC.

SAGE-B development was based in an open-source framework, Sahana FOSS (http://www.sahana.lk/). It required customizing some of original Sahana modules and creating new ones, tailored to dam-induced emergency management. The platform has a modular architecture developed in open and free technologies, which allows a continuous development and improvement accordingly to any changes that may be issued.

The current system contains data management of a dam, elements at risk and resources available. It also supports real-time management of dam-induced emergencies through integrated modules that help to define the level of alert of the dam, and the actions to pursue according to that level. Being a web-oriented system, SAGE-B integrates a geographic information system (GIS) through several technologies, like GoogleMaps, OpenLayers and MapServer. Emergency agents are some of the target users, and can use the GIS modules to track incidents and similar events.
\end{abstract}

Keywords: emergency preparedness and planning, emergency information systems. 


\section{Introduction}

Disaster is a broad term: it can be defined as a serious disruption of the functioning of a community or a society causing widespread human, material, economic or environmental losses that exceed the ability of the affected community or society to cope using its own resources [1]. Emergency is considered the resulting situation from the occurrence of a disaster. Based on the origin of their hazards, disasters can be classified into three main groups: natural, technological and man-made disasters. Earthquakes, floods, landslides, wind storms, droughts, and wild fires are some examples of natural disasters; industrial accidents, transport accidents and bomb explosions are some examples of technological disasters; and terrorist activities can be considered man-made disasters which may occur in the form of natural or technological accidents.

Disasters interrupt society by claiming lives, creating victims and destroying infrastructures and houses. When a disaster occurs, funds and budgets assigned for development purposes are diverted to respond to the consequences of that disaster and returning quality of life to normal. Disasters also have negative impacts on the environment as they affect natural resources. Therefore, considering society, economy and environment as three main components of sustainable development, disasters can have a negative impact on sustainable development. In this context an appropriate management of disaster is a necessity.

Of all natural disasters, floods are most frequent (46\%) and cause most human suffering and loss (78\% of population affected by natural disasters). They occur twice as much and affect about three times as many people as tropical cyclones [3]. A study of the United Nations University [4] shows that floods impact over half a billion people every year worldwide and might impact two billion by 2050 , of which a disproportionate number live in Asia (which hold $44 \%$ of all flood disasters worldwide and 93\% of flood-related deaths in the decade 1988-1997). According to a report of the World Water Council [5], flood and drought losses increased globally ten-fold (inflation corrected) over the second half of the $20^{\text {th }}$ century, to a total of around US\$ 300 billion in the 1990s. Since 2002, losses are estimated at US\$ 96 billion [3]. In general one third of humanitarian aid goes to flood related disasters and the European Commission alone has spent $€ 36$ million on floods since 2002 (excluding funds for the tsunami 2004) [5].

Taken the above paragraphs in mind, disaster and/or emergency management is defined as a cycle of activities including mitigation, preparedness, response and recovery. Mitigation efforts refer to those activities which reduce the vulnerability of society to the impacts of disasters. Preparedness efforts refer to those activities which make the government and disaster agents prepare for responding to a disaster, if it occurs. Response refers to the activities necessary to address the immediate and short-term effects of a disaster, which focus primarily on the actions necessary to save lives, to protect property, and to meet basic human needs. Relief, search, rescue, disaster fighting, medical service, permit control, sheltering, evacuation, law enforcement and many others are samples of disaster response activities. Recovery efforts refer to those activities that bring communities back to normal (such as infrastructure and house 
reconstruction) and they should be developed toward meeting mitigation and preparedness needs.

Mitigation and preparedness activities assume a crucial part, especially in emergency planning, which consists in the disaster definition scenarios; elaboration of resources lists and its characterization and categorization relevant to emergency response; and definition of actions to pursue with those resources according to the defined scenarios. The planning of the search and rescue activities constitutes an important part of the Civil Protection Entities. In most cases, the planning related to the disasters risks minimization is based in emergency plans. In Portugal, in the context of dam-break floods risk, the safety control, the emergency planning and the response management is regulated by law in large dams. This regulation states that those dams must have breach analysis studies, flood wave studies, flooding risk zones maps, and alert and warning systems. All these activities constitute basically the dam emergency plans that are an important tool in an emergency response situation.

According to [6], the aim of disaster response is to restore normal life as quickly as possible, with the initial stage of emergency response being both critical and immensely stressful. The extent of prior warning, and the ways in which this may allow avoidance or controlling actions to be taken are seen to be vital. The initial setting up of a critical control centre, the facilitating of mutual aid between the emergency services, the establishment of a cordon management system, and the formulation of wider communication structures are all initial elements of such an emergency response. According to [7], one of the successful outputs is rapid action, because response time is important for crisis situations and emergency services. Therefore, any problem or delay in information gathering and management has negative impacts on the quality of decisionmaking and hence on the quality and success of disaster response.

The disaster response processes complexity and its dynamics, allied to the volume of data/information to manage, either in a planning phase or in an emergency situation, suggests the use of information technology (IT). Indeed, the evolution and widespread use of information systems makes them the adequate tools to address these challenges in a dynamic way, overcoming the constant outdating of paper-based, fixed emergency plans.

\section{Conceptualization of emergency management systems}

Technology is rapidly providing capabilities that are dramatically changing our ability to prepare for and respond to extreme events [8], helping society to limit and manage crisis incidents [10]. Today, an emergency response system cannot be mentioned without support from information systems and technologies. These systems and technologies provide a new level of communication, learning, and action in complex systems [9]. Indeed, information technologies (IT) can help in disaster response, improving the information management in collecting information, analyzing it, sharing it, and disseminating it to the right people at the right time. Thus, IT will improve the response by helping people make 
better-informed decisions. Valid and timely information sharing is also critical in emergency response operations [11].

A number of IT research efforts have been targeted at the topic of emergency and disasters management with the aim to create modelling and simulation techniques and tools for the emergency management. The main purpose of IT use is information sharing among different entities, organizations, and people; resource (equipment, man power, money) planning and management; decision support for upper level administrators or managers; disaster and evacuation forecasting; effective and fast communication; administration and coordination of organizations and other related agencies; public education (internet); response team training; simulations of different disaster scenarios; damage assessment; notification and informing public during and after disaster occurrence; and dynamic and adaptive models for operational risk management $[12,13,15]$.

Several articles maintain that IT such as computer networks, virtual reality, remote sensing, GIS, and decision support systems are enhancing disaster communications.

Internet utilization for creating awareness, web pages to inform citizens, creating community discussion groups, making disaster plans available online, providing educational disaster management material to schools, libraries and other community related places, and providing support for training or drills can be used to address cultural factors. In recent years, governments have increased resources for the development of web-based emergency response systems and literature studies have shown the great complexities surrounding the design of this kind of systems [16]. However, the rush to develop this kind of applications can lead to the duplication of efforts and spend of resources looking for a solution that has been already implemented and proved in other environments or problems.

In this context, a few IT systems have been defined to manage emergency situations. Initiatives such as the Global Disaster Information Network (GDIN) provide evidence of the importance and the value of disaster-related information, as well as the need to be able to obtain and share it effectively. The aim of GDIN is to "provide the right information, in the right format, to the right person, in time to make the right decision" [20]. There are other systems that offer a more complex architecture, integrating geographic information systems, spatial databases and the internet [19], such as HUODINI [18], a platform for the integration and visualization of heterogeneous information for disaster management, which besides official information tries to integrate social networks systems information.

\section{SAGE-B system overview}

\subsection{Sahana framework}

Another IT system for emergency issues is the Sahana Free and Open Source Disaster Management System (http://www.sahana.lk). The Sahana FOSS was conceived during the December 2004 Asian Tsunami. It was developed to help manage the scale of the disaster and was deployed by the government's Center of 
National Operations (CNO) which included the Center of Humanitarian Agencies (CHA). Based on the success of the initial application and dire need for good disaster management solutions, particularly to handle large scale disasters, Swedish International Development Agency (SIDA) funded a second phase through the Lanka Software Foundation (LSF) to generalize the application for global use and to help in any large-scale disaster. The project grown to become a globally recognized project with deployments in many other disasters such as the Asian Quake in Pakistan (2005), Southern Leyte Mudslide Disaster in the Philippines (2006) and the Jogjarkata Earthquake in Indonesia (2006) [25].

The scope of the Sahana project was to be an integrated set of pluggable, web based disaster management applications that provide solutions to large-scale humanitarian problems in the relief phase of a disaster. This system had a few goals in helping in alleviating human suffering and helping saving lives through the efficient use of IT during a disaster; bringing together a diverse set of actors from Government, Emergency Management, NGOs, INGOs, spontaneous volunteers and victims themselves in responding effectively to a disaster; empowering the victims and their next of kin and better enabling them to help themselves; protecting victim data and reducing the opportunity for data abuse; and providing a Free and Open Source solution end-to-end available to everyone.

\subsection{Current work}

In the context of dam-break flood emergency management, a new information system, SAGE-B, was developed to help managing all the information within the dam's emergency plans. This information system, which will also be integrated with a flood emergency simulator, was structured in 11 modules (Fig. 1), eight of them are internal modules. The other three are possible add-ons, to expand the system in the future. They include: i) Reservoir and River basin data that are included in SNIRH, the National Water Resources Information System (http://snirh.inag.pt); ii) Dam Monitoring System; and iii) Dam Alert and Warning System.

SAGE-B development started in 2005, some of the modules were implemented as a proprietary Web Service based on a MySQL database and a PHP-based interface [21]. Since Sahana FOSS met some of the requirements defined for SAGE-B, namely on what concerns the Management of the Actions to be Developed, the Management of the Events, Occurrences and Alert levels, and the Management of Means and Resources to respond to the emergency, and includes a Web GIS (Geographic Information System) support, an adaptation of the original SAGE-B was developed to take advantage of the Sahana.

From the technological point of view, the Sahana FOSS is built in PHP with MySQL database (although it is also possible to use a PostgreSQL database), which can provide an environment to reuse, with some ease, most of the work that was previously accomplished. The modular framework that exists behind the Sahana Web Interface allows SAGE-B developers to build their dam specific (and emergency related) modules independently from those that already exist, and, at the same time, have a similar and customisable look and flexibility. Also, 


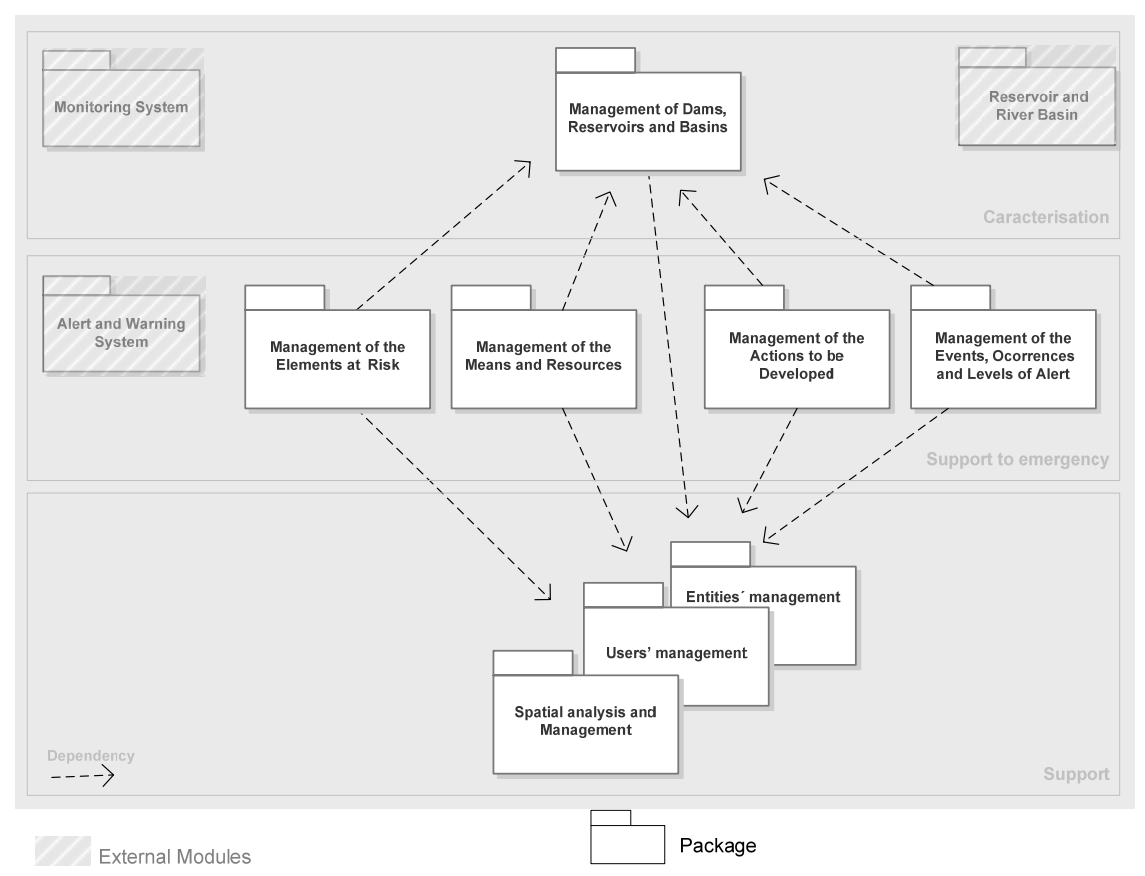

Figure 1: $\quad$ Structure of SAGE-B information system.

the modular framework deployment process of the Sahana FOSS allows choosing which modules shall be presented to users.

\subsection{GIS support}

Management of the aftermath of the disasters, along with disaster preparedness and mitigation involves dealing with heterogeneous information. Much of this information contains spatial components, which present a need for spatial analysis and visualization. A Geographic Information System (GIS) is a system for capturing, storing, analyzing and managing data and associated attributes which are spatially referenced to the Earth, and can be used for planning and decision-making. In SAGE-B, GIS support is an important requirement in order to help the Emergency Entities to spatially manage real-time incidents, or, for example, to consult the dam-break flood plains maps.

Sahana FOSS supports directly two ways of consulting spatial information through Google Maps and OpenLayers. Google Maps is a web mapping service application and technology provided by Google, for non-commercial use. It offers very complete street maps for numerous countries around the world. OpenLayers was created by MetaCarta after the O'Reilly Where 2.0 conference and is an open source JavaScript library for displaying map data in web browsers. It provides an API for building rich web-based geographic applications based in map data inserted by the user. 
Although OpenLayers offers more interaction options than GoogleMaps, neither of them can be considered a consistent GIS because both of them rely on the system having continuous access to the web. So other alternatives were studied.

Our current SAGE-B prototype adds a feature to what was supported through the Sahana Framework. It utilises MapServer, an open source development environment for constructing spatially enabled Internet applications [23]. A limitation of many present GIS-based Web services (including Google Maps and Openlayers) is that they lack interoperability and do not comply Web mapping specifications.

MapServer supports several scripting languages, including PHP, Perl and Python, and its notable features include: fully customizable with template driven output; feature selection by item/value, point, area or another feature (basic spatial query); supports tiled raster and vector data; map element automation (scalebar, reference map, and legend); scale dependent feature drawing and application execution; and on-the-fly projection.

MapServer also supports several Open Geospatial Consortium (OGC) Web specifications. OGC is an international industry consortium of 278 companies, government agencies and universities participating in a consensus process to develop publicly-available interface specifications [24]. OGC specifications support interoperable solutions that 'geo-enable' Web, wireless and locationbased services. These specifications empower technology developers to make complex spatial information and services accessible and useful with a variety of applications.

\section{Final considerations, research challenges and future plans}

A new emergency information system for dams, SAGE-B, was developed, taking advantage of complete and large knowledge in dam-breaking emergencies, based on existing emergency plans.

Other modules can be developed and be integrated in a near future to SAGEB. Several studies in IT use in emergency situations are currently in process. An example of IT utilisation in disaster manager involves its use in preparing agents to respond to a disaster. We are considering the use of IT in emergency warning systems in ways that they can potentially reduce the loss of life and property. So, instead of only using sirens to warning the population will be developing a multichannel emergency warning system that will use two non-traditional media: text messages through the public mobile phone network [22] and multimedia messages through the digital television network.

Other modules suggestions include flood wave real-time forecast or dambreaching real-time monitoring models. Or also an evacuation management module based on a multi-agent simulation model.

\section{Acknowledgements}

This study was supported and financed by Salva-Vidas Fundação para a Ciência e Tecnologia (FCT) Project 0602/014/15760. 


\section{References}

[1] ISDR, Basic Terms of Disaster Risk Reduction, International Strategy for Disaster Reduction, United Nations, http:/www.adrc.or.jp/publications/ terminology/top.htm, 2003.

[2] Mansourian, A., Rajabifard, A., Valadan Zoej, M.J. \& Williamson, I., Using SDI and Web-Based System to Facilitate Disaster Management, 2004.

[3] OFDA/CRED, 2005 disasters in numbers, OFDA/CRED, http://www.emdat.net, 2006.

[4] United Nations University, Two Billion People Vulnerable to Floods by 2050; Number Expected to Double or More in Two Generations Due to Climate Change, Deforestation, Rising Seas, Population Growth, http://www.unu.edu/news/ehs/floods.doc, 2004.

[5] De Groeve, T., Kugler, Z. \& Brakenridge, G.R., Near Real Time Flood Alerting for the Global Disaster Alert and Coordination System, In Proceedings of ISCRAM 2007, 2007.

[6] Williams, G., Batho, S. \& Russel, L., Responding To Urban Crisis: The Emergency Planning Response To The Bombing of Manchester City Centre, Cities, Vol.17, No. 4, 293-304, 2000.

[7] Inam, A., Institutions, Routines, and Crises: Post-earthquake Housing Recovery in Mexico City and Los Angeles, Cities, Vol. 16, No. 6, 391-407, 1999.

[8] Harrald, J.R., Raising Awareness: Informing and Educating the Public and Local Leadership. Early Warning Systems, Interdisciplinary Observations and Policies from a Local Government Perspective Symposium, A Public Entity Risk Institute, 2005.

[9] Comfort, L.K., Shared Risk: Complex Systems in Seismic Response, Amsterdam: Pergamon, 1999.

[10] Rinaldi, S., Peerenboom, J., and Kelly, T., Complexities in Identifying, Understanding, and Analyzing Critical Infrastructure Interdependencies, IEEE Control Systems Magazine, 11-25, 2001.

[11] Corbacioglu, S. and Kapucu, N., Organizational Learning and Selfadaptation in Dynamic Disaster Environments, Disasters, 30, 2, 212-233, 2006

[12] Beroggi, G.E.G. and Wallace, W.A., Operational Risk Management: $A$ New Paradigm for Decision Making, IEEE Transactions on Systems, Man, and Cybernetics, 24, 1450-1457, 1994

[13] Beroggi, G.E.G. and Wallace, W.A., Multi-Expert Operational Risk Management, IEEE Transactions on Systems, Man and Cybernetics Part C 30, 32-44, 2000

[14] Marincioni, F., Information Technologies and The Sharing of Disaster Knowledge: The Critical Role of Professional Culture, Disasters, 31, 4, 459-476, 2007

[15] Ozceylan, D. \& Coskun, E., Defining Critical Success Factors for National Emergency Management Model and Supporting the Model with 
Information Systems, Proceedings of the $5^{\text {th }}$ International ISCRAM Conference, 2008

[16] Kyng, M., Nielsen, E.T. \& Kristensen, M., Challenges in designing interactive system for emergency response, Proceedings of the $6^{\text {th }}$ ACM Conference on Designing interactive Systems, ACM Press, 301-310, 2006

[17] Montells, L., Montero, S., Díaz, P. \& Aedo, Ignacio, Mining Patterns for Web-based Emergency Management Systems, Proceedings ISCRAM2007, 133-138, 2007

[18] Fahland, D., Gläber, T.M., Quilitz, B., Weibleder, S. \& Leser, U., HUODINI - Flexible Information Integration for Disaster Management, Proceedings ISCRAM2007, 255-138, 2007

[19] Herold, S., Sawada, M. \& Wellar, B., Integrating Geographic Information Systems, Spatial Databases and the Internet: A Framework for Disaster Management, 2005

[20] GDIN (Global Disaster Information Network), GDIN Homepage, http://gdin.org, 2005

[21] Serrano, H. Sistema de Apoio à Gestão de Emergências do Aproveitamento de Alqueva, Faculdade de Ciências de Lisboa, 2005

[22] Palha-Fernandes, J., Emergency warnings with short message service, Nato Science for Peace and Security Series C - Environmental Security, 205-210, 2008

[23] University of Minnesota, Mapserver Homepage, http://mapserver.gis. umn.edu/, 2003

[24] OGC (Open Geospatial Consortium), http://www.opengeospatial.org/, 2005

[25] De Silva, C., Raschid, L., Careem, M., De Silva, R. \& Weerawarama, S., Sahana: Overview of a Disaster Management System, $2^{\text {nd }}$ International Conference on Information and AutomationS, 2006 